\title{
POMO- JA ETU-OHRIEN TUNNISTAMINEN
}

\author{
Osmo Ulvinen \\ Valtion siementarkastuslaitos, Helsinki
}

Saapunut 23. 12. 1971

\begin{abstract}
IDENTIFYING OF THE BARLEY CULTIVARS POMO AND ETU
\end{abstract}
Osmo Ulvinen

State Seed Testing Station, Helsinki

\begin{abstract}
Pomo and Etu are Finnish barley cultivars bred by the Agricultural Research Centre Department of Plant Breeding in Jokioinen. The year of releasing Pomo is 1968 and that of Etu 1970. The research carried out in the laboratory and on the experimental field of the Finnish State Seed Testing Station is concerned with the characters by which it is possible to identify the cultivars. The most important characters of Pomo and Etu are given in Table 1 and Figures $1-7$.
\end{abstract}

Uusimmat monitahoiset ohramme Pomo ja Etu ovat Maatalouden tutkimuskeskuksen kasvinjalostuslaitoksen tuotteita. Lajikkeet jatkavat sitä Jokioisten jalosteiden sarjaa, joka alkoi Paavo-ohran v. 1960 tullessa markkinoille. Näissä jalosteissa on samoinkuin Paavossa 2-tahoista "verta» ja muutenkin poikkeaa jalosteiden geneettinen rakenne meillä tavanomaisesta monitahoisesta ohrasta.

Pomo, joka tuli markkinoille v. 1968, polveutuu risteytyksestä (Voitto $\times$ Vega) $\times$ Bonus. Siinä on siis hyvin voimakas panos 2- tahoista ohraa (Voitto, Bonus). Pomon linjanumero oli Jo 0764. Etu tuli markkinoille v. 1970 polveutuen risteytyksestä Bonus M $\times$ Varde, ollen siis Bonuksen osalta Pomon sukulainen. Etu-ohran linjanumero oli Jo 0808.

Seuraavassa esitetään näistä lajikkeista ne tiedot, jotka Valtion siementarkastuslaitoksella lajikkeiden tunnistamistarkastuksissa sekä aitoustarkastuksissa on todettu. Pomo on ollut laitoksen laboratoriokokeissa ja koeviljelyssä (Viikin koetilalla) vuodesta 1962 ja Etu vuodesta 1965. Näitä lajikkeita toisiinsa verrattaessa on kuitenkin otettu huomioon vain vuodet, jolloin ne molemmat ovat olleet tarkastuksissa. Tähkiä koskevat tarkemmat tutkimukset on vuosittain tehty koekentältä otetusta 20 yksilöstä, joista jyvien yksityikohtaiseen tutkimukseen on käytetty tähkän keskivaiheilta otettuja keskitähkylän jyviä. Vuoden 1967 aineistosta ei näitä tutkimuksia ole tehty. 
Ennen tähkälle tuloa. Sekä Pomon että Edun alkukehitys on suhteellisen hidas. Pomolla oras on hyvin leveälehtistä, väriltään kellanvihreää. Joinakin vuosina voi Pomon oras olla luonnottoman kellervää, joka viittaa herkkyyteen viljelyolosuhteita kohtaan. Edun oras on selvästi kapealehtisempää ja tummemman vihreää kuin Pomolla. Normaalisti kehittyessään oraan väri on hyvin voimakkaan vihreä.

$\mathrm{T}$ äh källe t u lo. Pomo on tullut tähkälle keskimäärin 2.8 päivää myöhemmin kuin Paavo, joka on kehittynyt kylvöstä tähkälletuloon keskimäärin 53 vuorokaudessa. Vastaava arvo Edulla on +1 . Joinakin vuosina (selvimmin 1971) on Pomolla tullut runsaasti tähkiä esiin lehtitupen sivusta vihneet pahasti vääntyneinä. Lehtituppi on ehkä ollut liian ahdas paksulle tähkälle tai kehitys on ollut liian nopea.

Tä yd ellä tähkällä. Pomon keskipituus on ollut $80.2 \mathrm{~cm}$ ja Edun 70.9. Pituus on mitattu suoraksi vedettyjen yksilöiden tyveltä vihneiden kärkiin mikä selittää sen, että kasvustoissa ei ole suurempaa pituuseroa saatu. Pomon ja Edun luonnollinen kasvustojen pituusero on paljon suurempi, koska Edun tähkistö pian tähkälletulon jälkeen painuu voimakkaasti nuokulleen Pomon pysyessä terhakkaasti pystyssä. Erityisesti on Pomon pituus eri vuosina suuresti vaihdellut, onpa se eräänä vuonna (1969) ollut Etua lyhyempääkin. Tämä osoittaa selvästi, että Pomo on herkkä ulkoisille tekijöille. Täydellä tähkällä eroavat nämä lajikkeet myös vihneistön värin suhteen. Pomolla ovat vihneet miltei vihreät. Punaista antosyaaniväriä esiintyy hyvin niukasti. Edulla sensijaan ovat vihneet hyvin voimakkaan punertavat.

T u l e e n t u m in en. Pomon kehitys tähkälletulosta tuleentumiseen on ollut hieman Etua nopeampi, koska lajikkeiden keskimääräinen tuleentumisaika on miltei sama, 2.1 Pomolla ja 2.3 päivää Edulla Paavoa myöhäisempi. Aika kylvöstä tuleentumiseen on Paavolla ollut keskimäärin 95 vuorokautta. Tuleentumisvaiheessa Pomon vihneet karisevat herkästi. Joinakin vuosina on kasvusto ollut täystuleentuneena miltei vihneetöntä.

\section{Havaintoja kasviyksilöistä}

K orsi j a le h det. Hyvin leveälehtisellä ja paksukortisella Pomolla on korren solmuissa ja lehtien korvakkeissa antosyaaniväriä, mutta selvästi vähemmän kuin Edulla, jolla antosyaanin esiintyminen on erittäin runsasta. Edun lehdet ovat selvästi kapeammat kuin Pomolla eikä korsi niin paksu. Tähkän ja korren yhtymäkohdassa oleva »kaulus» on Edulla yleensä suljettu, Pomolla taas avoin tai v-muotoinen.

T ähkä. Tähkästä suoritettujen tutkimuksien tulokset on esitetty taulukossa 1 . Tähkän tiheyden perusteella kuuluvat Pomo ja Etu eri muunnoksiin. Pomon tähkä on tiheä, pyramidimaisesti kärkeen kapeneva (kuva 1). Tähkälapakon jaokkeen keskipituus on $2.1 \mathrm{~mm}$, joten Pomo on 6-tahoinen tähtiohra kuuluen muunnokseen densum Ser. (pyramidatum Körn). Edun tähkä taas on Pomoa harvempi tasaleveä (kuva 2), lapakon jaokkeen keskipituuden ollessa $2.6 \mathrm{~mm}$. Tämän perusteella Etu on 6-tahoinen tasapaksu ohra, var. parallelum Körn. (MANSFeld 1950, Ulvinen 1963). Kuten aikaisemmin on mainittu on Pomon tähkä hyvin pysty ja vähäantosyaaninen, Edun taas voimakkaasti nuokkuva ja erityisesti vihneessä on runsaasti antosyaania. Tähkälapakossa on lajikkeilla muutakin eroavuutta kun vain jaokkeiden pituus. Pomon jaokkeet ovat yleensä paksum- 


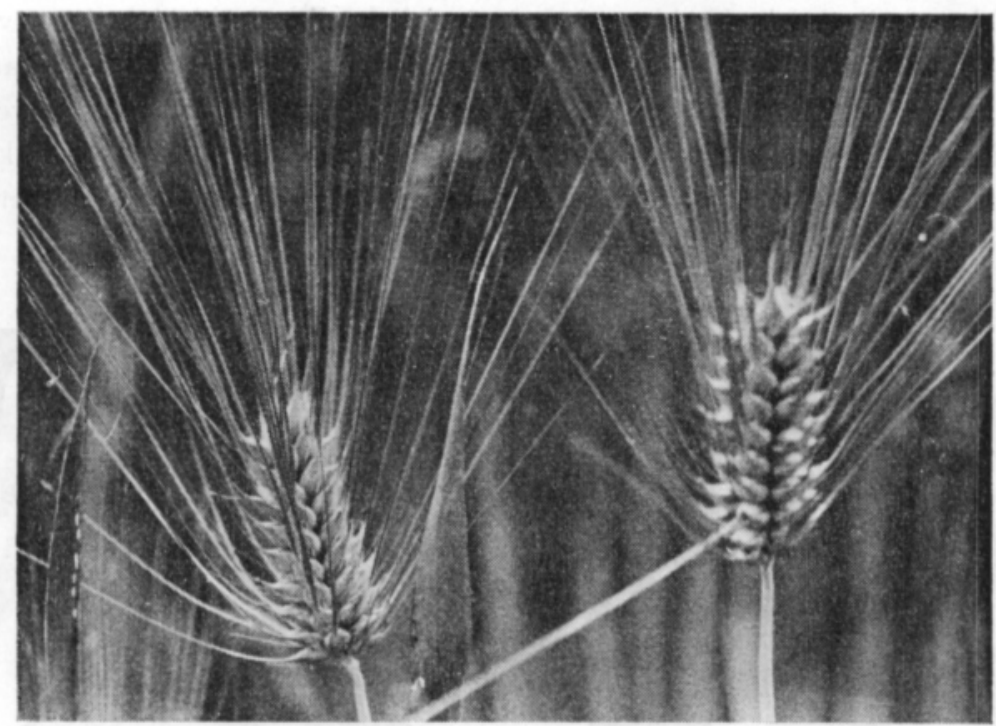

Kuva 1. Pomo on 6-tahoinen tähtiohra [var. densum Sér. (pyramidatum Körn.)]. Tähkä on tiheä, pysty. Fig. 1. The ear of Pomo is dense six-row and erect.

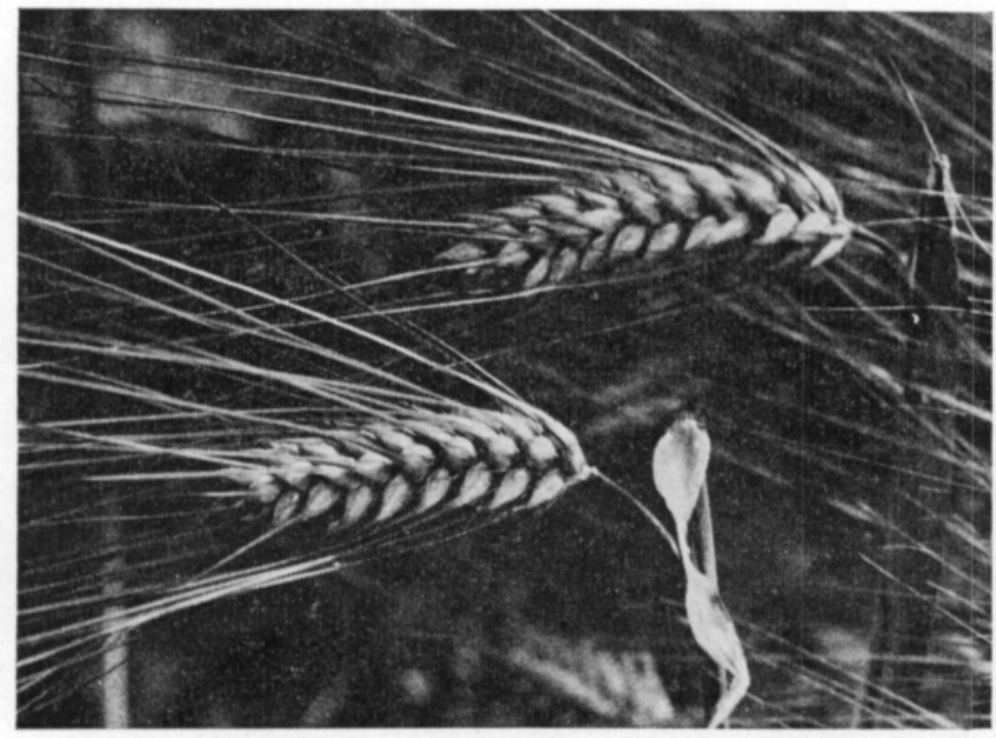

Kuva 2. Etu on 6-tahoinen tasapaksu ohra (var. parallelum Körn.). Tähkä on Pomon tähkää harvempi, voimakkaasti nuokkuva.

Fig. 2. The ear of Etu is six-row but laxer than that of Pomo and srongly nodding. 
mat kuin Edun ja lisäksi jaokkeiden alapäässä ei Pomolla ole jyrkkää kaarevaa reunaa, mikä taas on Edulle ominaista (kuva 3). Pomo ja Etu eroavat toisistaan siis saman tuntomerkin perusteella kuin Tammi ja Otra (Ulvinen 1959). Tähkälapakon reunoissa on sekä Pomolla että Edulla runsaasti pitkiä karvoja. Kaleet ovat Pomolla keskimäärin pitemmät kuin Edulla. Molemmilla kaleiden keskipituus on pienempi kuin muilla monitahoisilla lajikkeillamme.

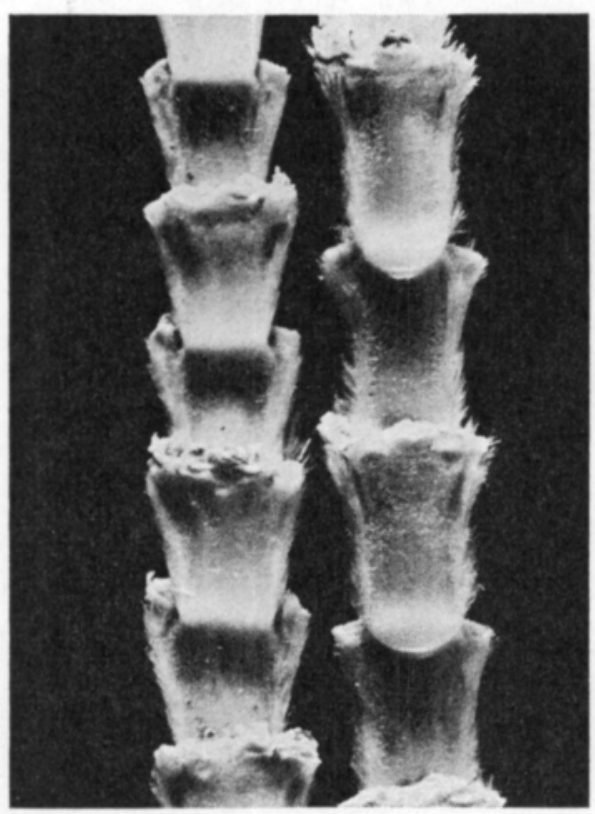

Kuva 3. Etu-ohran tähkälapakon (oikealla) jaokkeiden alapäässä on jyrkkä, kaareva reuna, kun taas Pomon jaokkeet (vasemmalla) liittyvät toisiinsa loivasti.

Fig. 3. The segments of Etu's rachis (right) have a sharp, curved edge in their lower end while the segments of Pomo (left) are attached gently slopingly to each other.

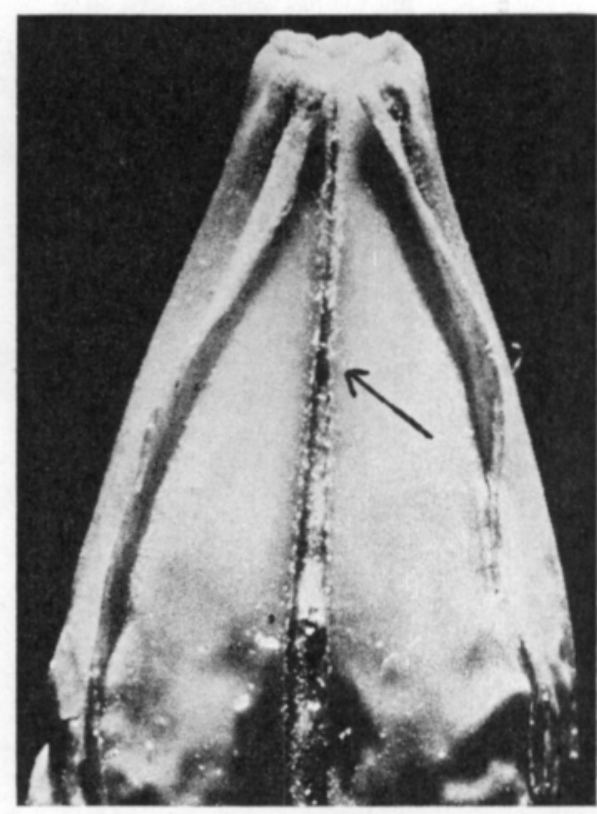

Kuva 4. Edun jyvässä on vatsavaon reunoissa pientä nukkaa, joten se kuuluu meillä harvinaiseen pilosum-tyyppiin.

Fig. 4. The grain of Etu has short hairs on the edges of the ventral furrow thus belonging to the so-called pilosum-type which is uncommon in Finland.

\section{7yvä}

Jyvästä suoritettujen tutkimuksien tulokset on esitetty taulukossa 1 .

T y v is u k a n e n on sekä Pomon että Edun jyvissä pitkäkarvainen. Tässä suhteessa ne poikkeavat kaikista muista suomalaisista monitahoisista lajikkeista, koska muilla tyvisukasen karvat ovat lyhyet (kuva 5). Pitkäkarvainen tyvisukanen on dominoivana ominaisuutena periytynyt Pomon ja Edun 2-tahoisilta vanhemmilta.

S i v u s e lkä s u o n e t ovat Pomolla ja Edulla väkäselliset, mikä taas on lajikkeiden monitahoisten vanhempien (Pomolla Vega ja Edulla Varde) perua. Väkästen lukumäärä on Edulla (keskim. $18.6 \mathrm{kpl}$ ) osoittautunut selvästi suuremmaksi kuin Pomolla (keskim. $7.6 \mathrm{kpl}$ ). Edulla on selvien väkästen lisäksi helpeiden suonissa ja muuallakin helpeissä runsaasti hyvin pieniä väkäsiä. 
Taulukko 1. Pomo- ja Etu-ohrien tähkän ja jyvän eräiden ominaisuuksien vuosittaiset keskiarvot ja kokonaiskeskiarvo.

Table 1. Annual averages and total average of certain studied characters of ear and grain in cultivars Pomo and Etu.

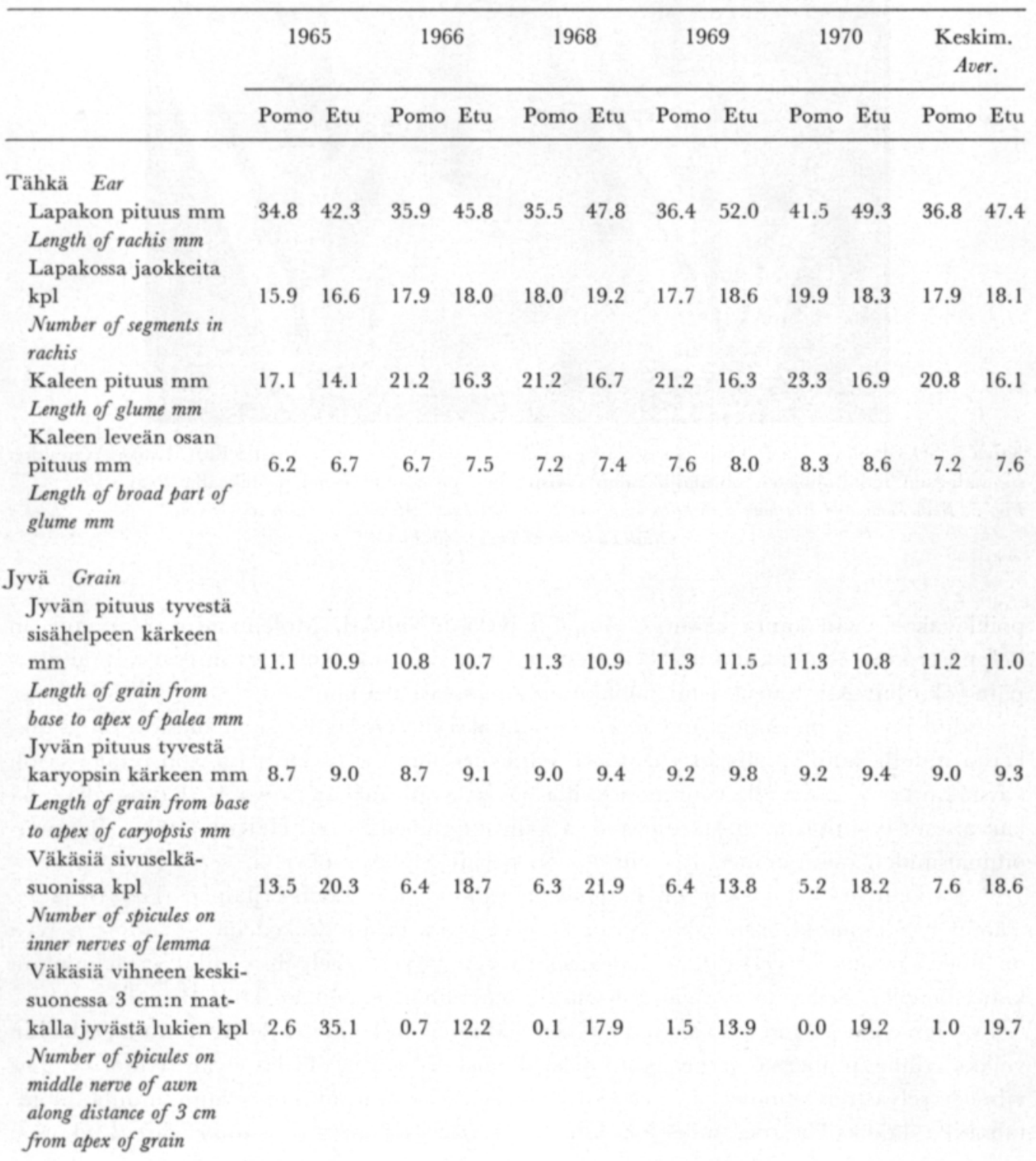

Edelläesitetyn perusteella voidaan todeta, että Pomon ja Edun jyvät kuuluvat klassillisessa luokittelussa tyyppiin $\beta$ (b) (Atterberg 1891, Bolin 1893, SAuli 1927).

J y vän kannan rakenne on Pomo- ja Etu-ohrilla 6-tahoiselle tyypille ominainen, mutta eroavat ne kuitenkin oleellisesti toisistaan. Pomon kannassa on miltei aina jyrkkä poikittainen vako, joka on Edulla harvinainen. Edun kannassa ei tavallisesti ole 


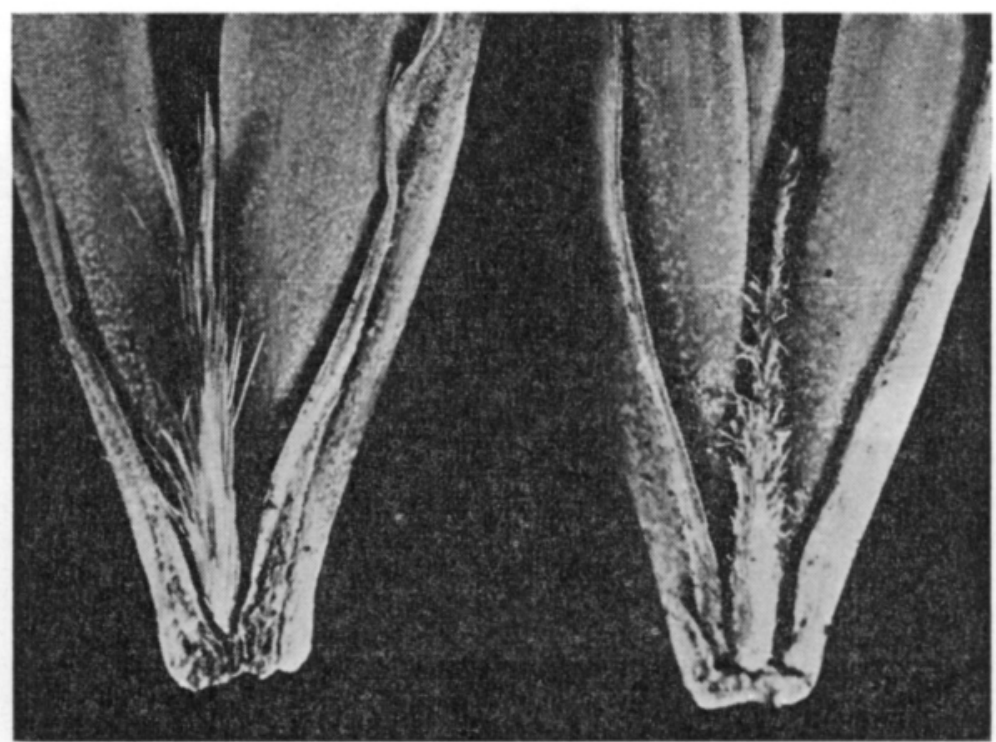

Kuva 5. Sekä Pomon että Edun jyvän tyvisukanen on pitkäkarvainen (vasemmalla Etu). Kaikkien muiden suomalaisten monitahoisten ohralajikkeiden tyvisukanen on lyhytkarvainen (oikealla Paavo).

Fig. 5. Both Pomo and Etu have a rachilla with long hair (left Etu). All other Finnish six-row barley cultivars have a rachilla with short hairs (right Paavo).

poikkivakoa vaan kanta kääntyy ylöspäin jyrkästi valliksi. Molemmat kantatyypit on helppo erottaa 4- tahoisilla lajikkeilla esiintyvästä tyypistä. Niillä jyvän tyvi taipuu alaspäin joko loivaksi kouruksi tai puolikuunmuotoiseksi painanteeksi.

Edun jyvässä on ominaisuus jota ei toistaiseksi ole esiintynyt suomalaisista ohralajikkeista muulla kuin vähäisessä määrässä Vankkuri-ohralla. Jyvän vatsavaon reunoissa on varsinkin tyvisukasen alla suurennuslasilla havaittavaa nukkaa (kuva 4). BERGAL käyttää karvaisesta tyypistä nimitystä pilosum ja kaljusta glabrum (ref. HunTer 1952). Pilosumominaisuuden esiintyminen Etu-ohralla on perintöä Varde-ohralta.

Jyvien ulkonäkö on Pomolla ja Edulla suhteellisen erilainen (kuva 6 ja 7). Tähän lyö leimansa ensinnäkin jyvän kannan eroavaisuus (ks. edellä). Etu-ohran jyvä on lisäksi pituuteen verrattuna kapeampi ja ryppyisyyttä helpeissä esiintyy yleisemmin kuin Pomolla. Selkäsuonet ovat Etu-ohralla enemmän kohollaan kuin Pomolla.

Vihneen ominaisu udet on lähinnä laskettava jyvän tuntomerkkeihin vaikka vihne puitaessa katkeaakin. Sekä Pomo- että Etu-ohrilla ovat sivutähkylöissä vihneet selvästi lyhemmät kuin keskitähkylässä. Ero on suurempi kuin muilla monitahoisilla lajikkeillamme, mikä on laskettava pääosaltaan sen voimakkaan 2-tahoisen perinnön ansioksi, mikä Pomolla ja Edulla on. Keskisuonen hampaallisuutta vihneen tyvellä on menestyksellisesti käytetty hyväksi ohran lajiketuntomerkkinä (HELlBo 1927, Korpinen 1936 ja 1943). Tässä suhteessa poikkeavat Pomo ja Etu selvästi toisistaan. Vihneen keskisuonessa ei Pomo-ohralla ole $3 \mathrm{~cm}: n$ matkalla jyvän kärjestä luettuna juuri ollenkaan väkäsiä (keskim. $1.0 \mathrm{kpl}$ ), kun sensijaan Edulla näitä on runsaasti (keskim. $19.7 \mathrm{kpl}$ ). Selvien väkästen lisäksi Edulla on mikroskooppista väkäsellisyyttä runsaasti vihneen keskisuonessa. 


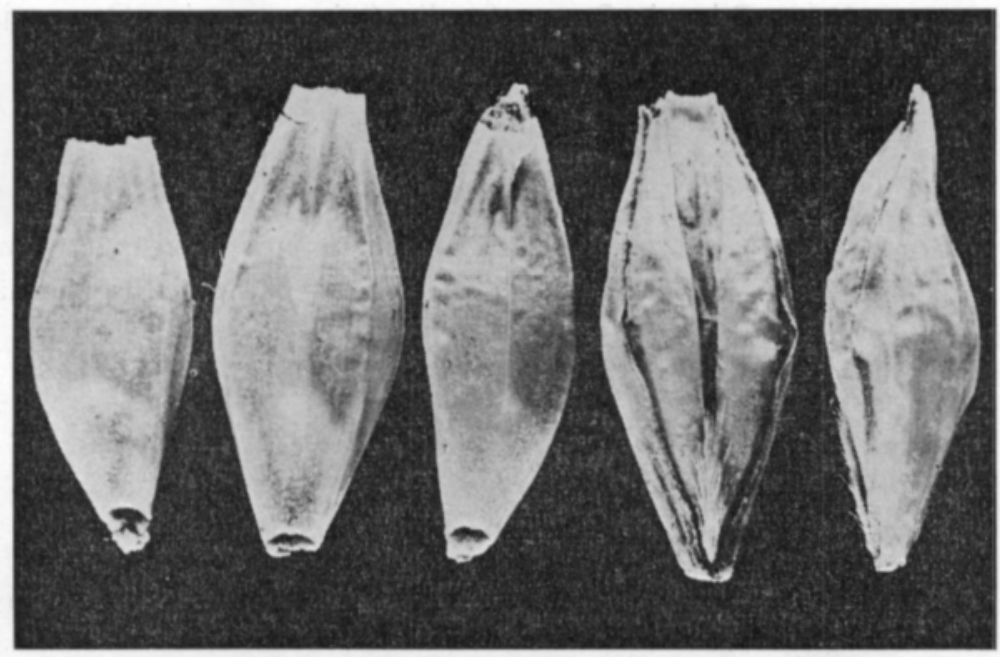

Kuva 6. Pomon jyvä on paksuhko, sileä. Jyvän kannassa on jyrkkä poikittainen vako. Fig. 6. The grain of Pomo is fairly thick, even. There is a sharp transversal furrow in the base of the lemma.

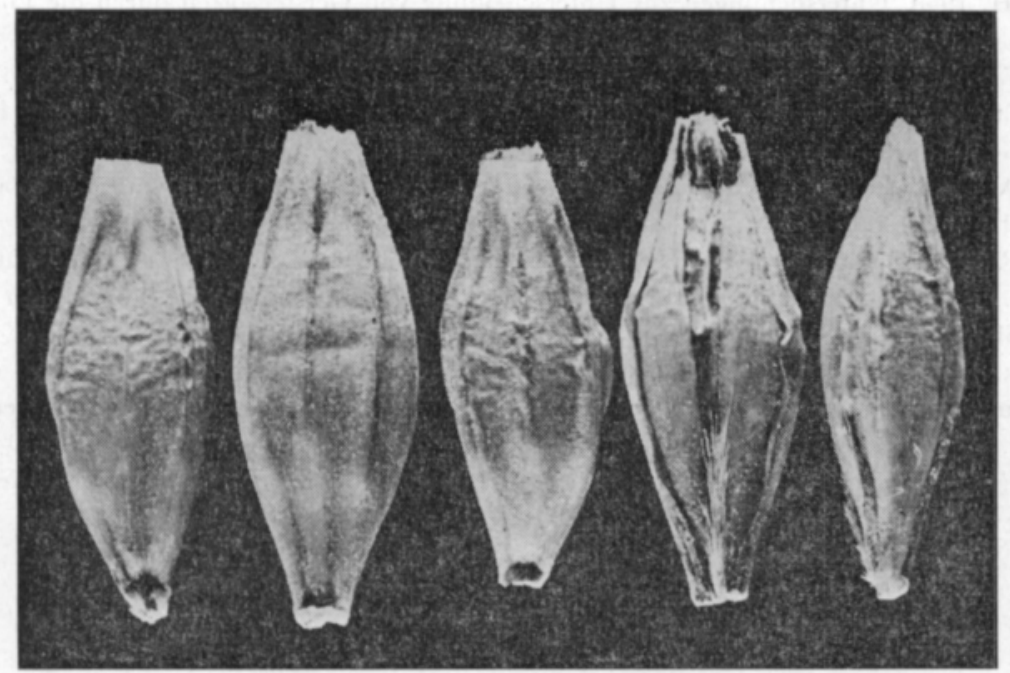

Kuva 7. Edun jyvä on Pomon jyvää laihempi, suonet usein kohollaan ja ryppyisyyttä helpeissä esiintyy usein. Jyvän kanta kääntyy useimmiten ylöspäin jyrkästi valliksi.

Fig. 7. The grain of Etu is thinner than that of Pomo, the nerves of the lemma are often raised up and the lemma and palea are often wrinkled. The base of the lemma generally turns up and forms a steep edge.

Jyvien fenolireaktioss a (Listowski 1936, Hänsel 1958, Steinberger 1958) ei meikäläisillä lajikkeilla ole todettu suuriakaan eroja. Etu ja Pomo reagoivat Paavon tapaan ollen muita monitahoisia lajikkeitamme hieman tummempia. Tässä heijastuu lajikkeiden 2- tahoinen perintö, koska yleensä 2-tahoiset ns. nutans-tyyppiset ohrat, joita Voitto ja Bonus ovat, reagoivat fenolissa voimakkaammin kuin monitahoiset 
lajikkeet (Listowski 1936). Edun ja Pomon fenolireaktion ero esim. Otraan ja Pirkkaan on niin vähäinen, ettei sillä ole käytännössä merkitystä.

\section{Yhteenveto}

Pomo- ja Etu-ohrat eroavat selvästi sekä toisistaan että kaikista muista Suomessa viljeltävistä lajikkeista, joten niiden aitouden valvonta yhtenäisinä ja itsenäisinä lajikkeina on suhteellisen helppoa.

\section{KIRJALLISUUTTA}

Atrerberg, A. 1891. Die Klassifikation der Saatgersten Nord-Europas. Landw. Vers. Stat. 39: 77-80.

BoLıs, P. 1893. Renodling af ett antal kornformer med olika botaniska kännetecken. Alm. sv. Utsädesför. Tidskr. 3: 20-25.

HELLBo, E. 1927. Några undersökningar rörande sortkännetecken hos trenne olika kornsorter av nutanstyp. Medd. Stat. Centr. Frökontr. anst. 2: 80-85.

Hunter, H. 1952. The barley crop. Crosby Lockwood a. Son., London 187 s.

HänsEL, v. H. 1958. Untersuchungen zur Unterscheidung von Gerstensorten durch die Phenolreaktion. Mitt. der Versuchsstat. für das Gärungsgewerbe. 12. Jahrg. n:o 9/10: 74-77.

KoRPINEN, ELLI 1936. Eräistä ohralaatujen laatutuntomerkeistä. Maatal. tiet. aikak. 1936: 69-88.

KORPINEN, ElLi 1943. Ohran morfologisista ominaisuuksista. Referat: Uber morphologische Eigenschaften der Gerste. Maatal. tiet. aikak. 15: 49-63.

Listowski, A. 1936. Die Unterscheidung der Gerstensorten durch Phenolfärbung der Körner. Angew. Bot. 18: 142-148.

MAnsfeld, R. 1950. Das morphologische System der Saatgerste, Hordeum vulgare L.s.l. Züchter 20: 8-24.

SAULI, J. O. 1927. Suomen maatiaisohrat ja niiden jalostusarvo. Referat: Die finnischen Landgersten und ihr züchterischer Wert. S. maatal. tiet. seur. julk. 16: 1-139.

Steingerger, J. 1958. Zur Methodik der Unterscheidung österreichischer Gerstensorten durch Kornmerkmale. Jahrb. 1958 der Bundesanstalt für Pflanzenbau und Samenprüfung in Wien, ss. 19-29.

Ulvinen, O. 1959. Otra-ohra, tuleeko se isäänsä vain äitiinsä? Pellervo 19-20/1957: 960-961.

ULVINEN, O. 1963. Suomessa viljeltyjen ohralajikkeiden systemaattinen asema. Maatal. tiet. aikak. 35: 127-137. 